\title{
Dynamic Response of FOC Induction Motors Using MTPA Considering Voltage Constraints
}

\author{
Alexander Popov \\ Department of Electronics and nanoelectronics \\ OGAREV MORDOVIA STATE UNIVERSITY \\ Saransk, Russia \\ alalpopov91@mail.ru
}

\author{
Igor Gulyaev \\ Department of Electronics and nanoelectronics \\ OGAREV MORDOVIA STATE UNIVERSITY \\ Saransk, Russia \\ ivgulyaev@mail.ru
}

\begin{abstract}
Maximum torque per ampere (MTPA) strategies are aimed to improve the efficiency of induction motor (IM) which regularly operate at low load levels; however, these strategies penalize the dynamic, due to the need to remagnetize the machine when the torque must be increased. Dynamics of torque during remagnetization are strongly conditioned by current constraints, and also by voltage constraints when the machine operates at high speeds. Once torque dynamics must be limited, torque during remagnetization process can be profiled to follow a ramp to reduce jerk. It is needed in this case to determine the minimum settling time (maximum slope of the torque ramp) achievable by fully exploiting the current limits of machine and inverter. However, when remagnetization occurs at high speeds, current regulator will be subjected to voltage constraints. This paper deals with the selection of overmodulation strategies during the remagnetization process, with the aim of guaranteeing proper operation of the current regulator under severe voltage constraints.
\end{abstract}

Keywords - AC machine, asynchronous motor, digital control, electrical drive, highly dynamic drive, induction motor, optimal control, prognosis, regulation, simulation, voltage constraints.

\section{INTRODUCTION}

Electric drives using induction motors (IM) often operate at their rated flux for speeds below rated speed, and implement an $1 / \omega$ law (or similar) in the field-weakening region. This strategy provides a fast-dynamic response, but at the price of increased joule losses when the machine operates with light load levels for long periods of time.

Efficient operation of electric drives is very important in many industrial applications. Different methods have been proposed in the literature for this purpose. The conventional maximum torque per ampere (MTPA) control method is well studied and easy to implement in practice. It is applicable in situations when machine operates with low load for a long period of time. The efficiency of MTPA is achieved by reducing the flux level according to load torque. However, compared to the classic field-oriented control (FOC) which use a constant rotor flux, MTPA have low dynamic performance due to the large time constant between the stator $\mathrm{d}$-axis current and the rotor flux.

\footnotetext{
This research was performed with the support of the Russian Science Foundation grant (project 15-19-20057)
}

\author{
Viktoriya Popova \\ Department of Electronics and nanoelectronics \\ OGAREV MORDOVIA STATE UNIVERSITY \\ Saransk, Russia \\ popovava@mrsu.ru
}

\author{
Fernando Briz, Senior Member, IEEE \\ Department of Electrical Engineering \\ UNIVERSITY OF OVIEDO \\ Gijon, Spain \\ fbriz@uniovi.es
}

Since the dynamics of torque will be limited during remagnetization process, torque can be profiled to achieve two targets: minimize the settling time, which is achieved by using all the available current during the whole transient, and minimize the jerk and consequently the stress of the mechanical transmission, which is achieved by following a ramp for the torque command. Discussion of this strategy can be found in [1].

A relevant aspect which must be consider for the described strategy is that the process of remagnetization might occur with the inverter operating close to (or even at) its voltage limit. Saturation of the current controller, and the use of overmodulation strategy being implemented will have a major impact on the performance of the method.

This paper analyzes overmodulation strategies during the remagnetization process. The paper is organized as follows. MTPA and torque dynamics are briefly reviewed in Section II. Torque profiling during remagnetization is revised in Section III. Torque profiling also considering voltage constrains is studied in Section IV. Simulation results are provided in Section V, the conclusions being summarized in Section VI.

\section{INDUCTION MACHINE BEHAVIOR}

\section{A. Regions of operation of the induction machine}

The Fig.1 shows the general block-diagram of FOC induction motor. The torque command transforms into d-and $\mathrm{q}$-axis current commands following the proposed below algorithm. The complex current regulator is used to produce voltage commands and ensure stability of the system. The current and voltage constraints are assessed in accordance with initial and final operation point.

There are several regions, depending on the rotor speed and constraints that apply in each case. The first one is operating with low speed. At this region only current constraints should be taking into account. The backEMF is low, so there enough voltage to produce the rated flux and current. The machine can provide its rated torque without 


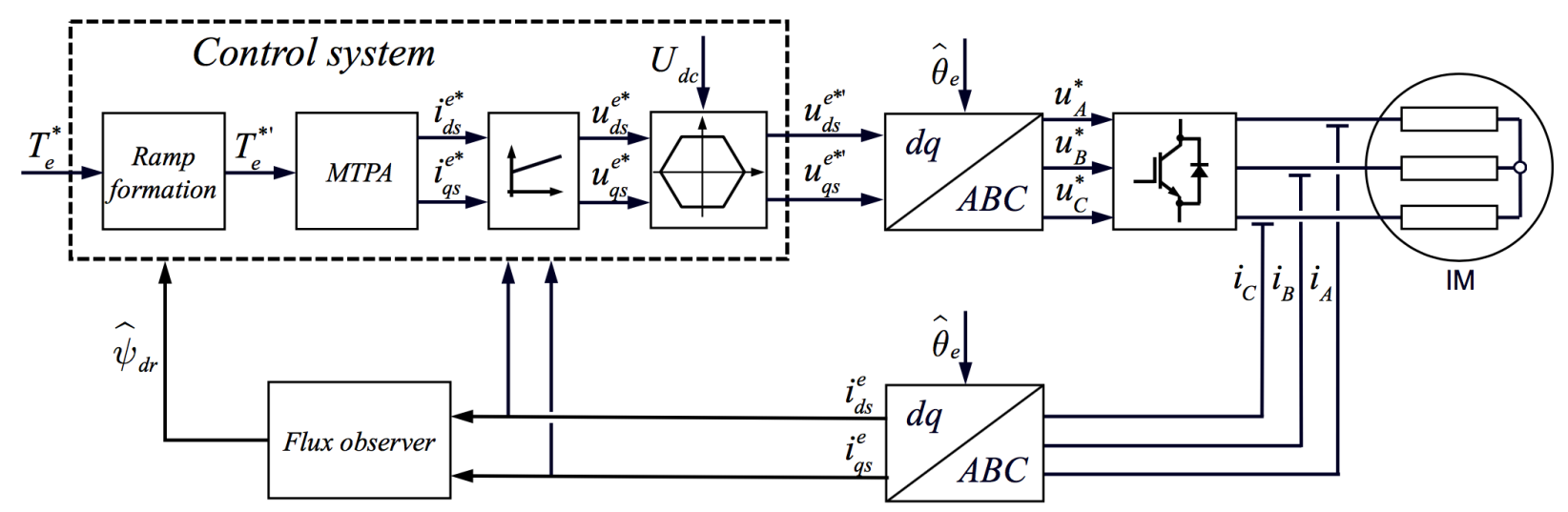

Fig. 1. General block diagram of a FOC IM, including proposed command genegation block, synchronous PI current regulator, voltage limitation block and inverter, current model based flux observer

going beyond the voltage limits. From the medium speed to rated speed, machine can also provide its rated torque in steady state, but the changes in the current commands can require a transient voltage larger than available in the inverter. The whole region, from low speeds to rated speed can be called as constant torque region. In the constant power region machine operates with speeds above the rated to high speed. The voltage and current limits should be considered. Furthermore, the serious degradation of the current regulator response can be observed at this region. At the very high speed machine operates below its current limits, so the only voltage constrains are used.

\section{B. Maximum torque per ampere (MTPA)}

The torque equation of the induction is given in (1). In steady state, the equation can be rewritten as a function of the d- and q-axis currents (2).

$$
\begin{aligned}
& T_{p}=\frac{2}{3} \cdot p \cdot \frac{L_{m}}{L_{r}} \cdot \psi_{d r} l_{q s} \\
& T_{\mathbf{e}}=\frac{2}{3} \cdot \boldsymbol{p} \cdot \frac{L_{m}^{2}}{L_{r}} \cdot \boldsymbol{i}_{\mathrm{ds}}^{e} \cdot \boldsymbol{i}_{\mathrm{qs}}^{\mathbf{e}}
\end{aligned}
$$

It is readily observed from (2) that to obtain the maximum torque per ampere, $\boldsymbol{i}_{\mathbf{s} \boldsymbol{d}}^{\boldsymbol{e}}=\boldsymbol{i}_{\mathrm{ss}}^{\mathbf{e}}$. This condition can be hold for values of $i_{s q}^{e}$ below the rated d-axis current. Beyond that point, $i_{s d}^{e}$ cannot be increased further, as the machine will saturate, meaning that the increase of the current will not result in a rotor flux (and therefore torque) increase.

\section{Rotor flux and stator current dynamics}

While (2) is useful to illustrate the physical principles of MTPA, this equation hides the dynamics of the rotor flux, which will play a key role determining the dynamic response of the drive. The equation describing the rotor flux as a function of the d-axis current is (3), the corresponding transfer function being (4). Rotor flux dynamics are seen to depend on rotor time constant $\tau$, which can be in the range of several tens milliseconds to several hundred milliseconds, depending on the machine size.

$$
\begin{gathered}
\frac{d \psi_{d r}^{e}}{d t}=\frac{L_{m} i_{d s}^{e}-\psi_{d r}^{e}}{T_{r}} \\
\frac{\psi_{d r}^{e}}{i_{d r}^{e}}=\frac{L_{t h}}{\tau_{r} s+1} \quad ; \quad \tau_{r}=\frac{L_{r}}{R_{r}}
\end{gathered}
$$

On the other hand, stator current dynamics can be modeled as a first order system (4), $b w$ being the bandwidth in radians per second of the current regulator.

$$
\frac{i_{d q s}^{e}}{i_{d q s}^{e^{*}}}=\frac{1}{(1 / b w) s+1}
$$

Values for the bandwidth in the range of several hundred $\mathrm{Hz}$ are usual in modern electric drives using synchronous PI current regulators. This results in settling times for the current in the range of a few milliseconds.

It is concluded from the previous discussion that operation with MTPA will necessarily penalize the dynamic response of the machine due to the need to rebuild the rotor flux. An example of used in this paper current control is shown in Fig. 2. The MTPA strategy is applicable while the nominal values of $\mathrm{d}$-axis current will be reached. From the point of nominal $i_{s d}^{e}$ to rated frequency of the rotor, the constant flux is used. In the flux weakening region I the voltage constraints were reached in steady state. To maintain the maximum torque and further increase speed, the q-axis current should be increased, at the same time as d-axis current will reducing. Under current constraints it will look like circle section in Fig.2. In the second flux weakening region the current vector shall be established in accordance with only voltage constraints.

The transition between one point of MTPA section to another one is time consuming operation. The use of final current values for regulator will lead to long transient process, as shown in Fig.3. Improved strategies for remagnetization of the machine are discussed in the next section. 


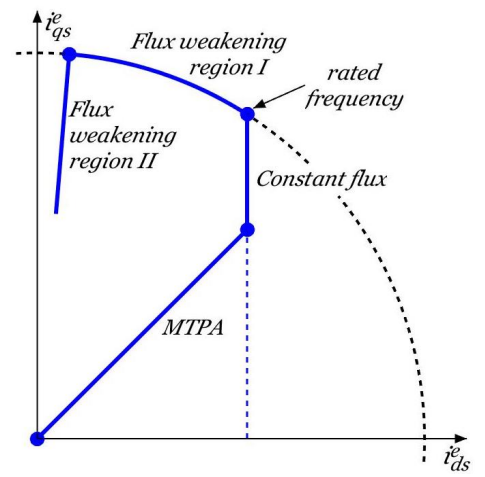

Fig. 2. Thajectory of the current vector in a dq-plane (steady state) while the rotor speed changes from zero up to very high speed.

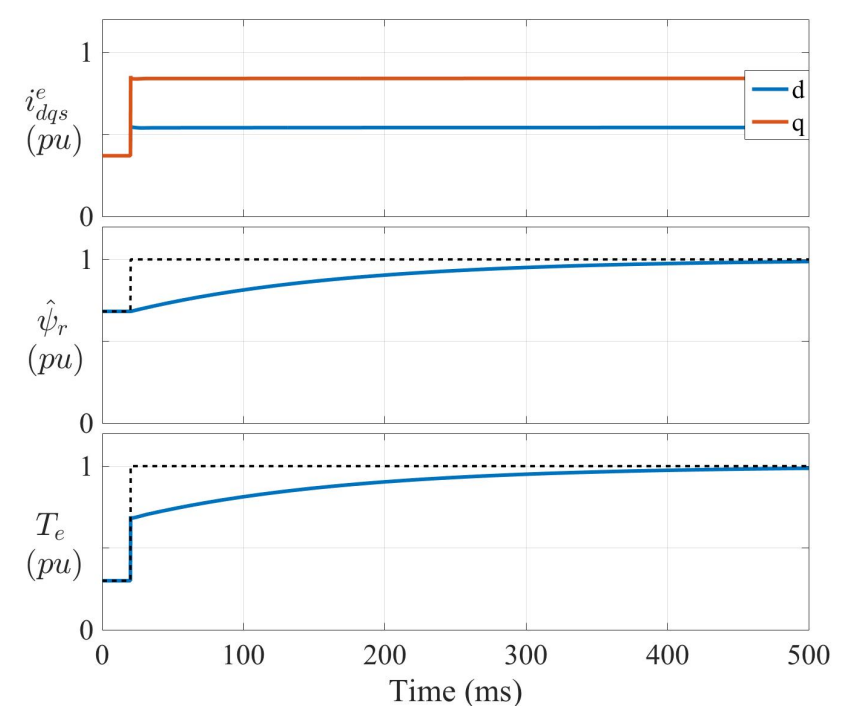

Fig. 3. Simulation results. Flux and torque response when the machine is remagnetized using rated $\mathrm{q}$ and $\mathrm{q}$-axis cyrrents. From top to bottom: dq currents, rotor flux, torque.

\section{TORQUE PROFILING DURING REMAGNETIZATION UNDER CURRENT CONSTRAINTS}

As discussed before, if the machine operates with reduced flux, it is not possible to produce torque quasiinstantaneously (i.e. following the stator current dynamics). Instead, the machine must be magnetized first, following the much slower rotor flux dynamics. It can be advisable to use profiled torque commands (e.g. ramp) instead of a step - like commands. This type of profiles will be beneficial e.g. when the machine is connected to mechanical transmissions with gears, it will reduce the mechanical stress. Moreover, incremental command of torque made it possible to allocate more current at the begin for d-axis current, which in turn leads to the more rapid increase of rotor flux.

Fig. 4 shows the result of proposed algorithm simulation. For a given target torque, the algorithm estimates first the available torque slope. Based on it the new torque command is produced, and q-axis command is determined. According to the algorithm and current constraints, all available current has used in d-axis to produce required flux as fast as possible. At the end of transient process the current commands reach it's rated values.

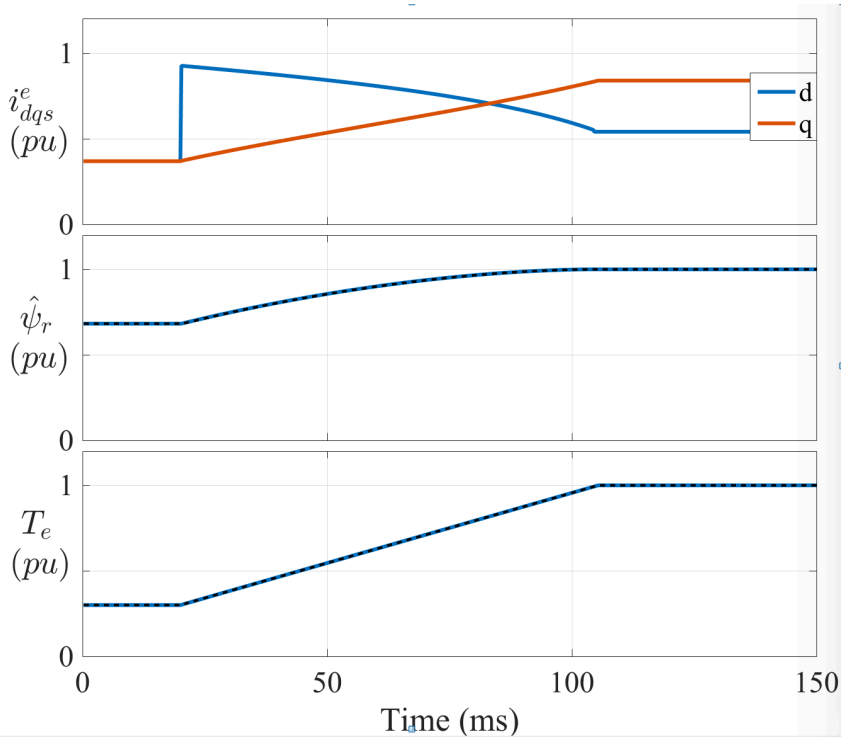

Fig. 4. Simulation results. Transient response using a ramp-like torque command from $0.3 \mathrm{pu}$ to $1 \mathrm{pu}$. The machine was initially demagnetized. From top to bottom: dq currents, rotor flux, torque.

\section{TORQue Profiling CONSIDERING Voltage CONSTRAINTS}

Previous section addressed calculation of the current trajectories needed to provide the desire torque ramp. Those currents will be the command for the current regulator. Tracking those commands when the machine operates at high speeds will require the use of all the available voltage. A key design issue in this regard is the modulation strategy used in the inverter, and more specifically to decide if overmodulation (including six-step operation) are allowed. The overmodulation will be used only during the transient process. At the steady state, the current commands are such that they can be followed with the inverter working in the linear region.

The voltage margin is directrly related to the inverter DC-link voltage and can be expressed as a hexagon whose magnitude is equal to $2 / 3 U_{\mathbf{a}}$. The linear region, for this part, can be shown as a circle wich radius equal to $1 / \sqrt{3} U$. The voltage reference vector is rotating in stationary voltage plane. If it goes beyond the voltage hexagon, overmodulation method shoud be used.

The slope coefficient K2 obtained in [2], consider only current constraints. So, there are two options to take into account the voltage limits. The first one is use "old" K2 and some overmodulation strategy when required voltage goes beyond the linear operation region. The second one is obtain $\mathrm{K} 2$ considering also voltage constraints at ones. In this paper we are using first, whereas second is a subject of ongoing research.

\section{A. Overmodulation methods}

Fig.5 shows three well-known methods: minimum phase error, minimum distance and six-step overmodulation. The modulation index (MI) is used to compare their. At Fig.6 shown the relation of $\mathrm{MI}$ and $\mathrm{MI}^{*}$, where $\mathrm{MI}^{*}$ determine the magnitude of voltage reference vector. 


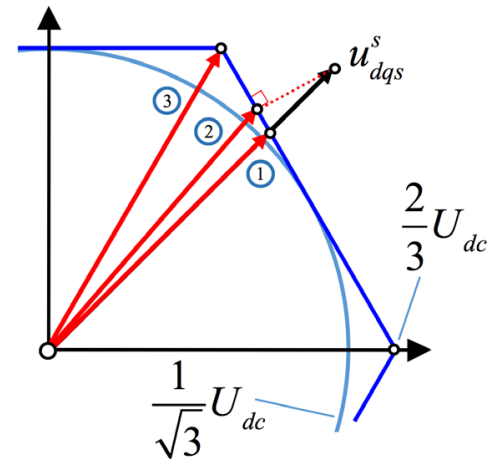

Fig. 5. Voltage limits of the inverter. Linear limit (inscribed circle), and different methods of overmodulation

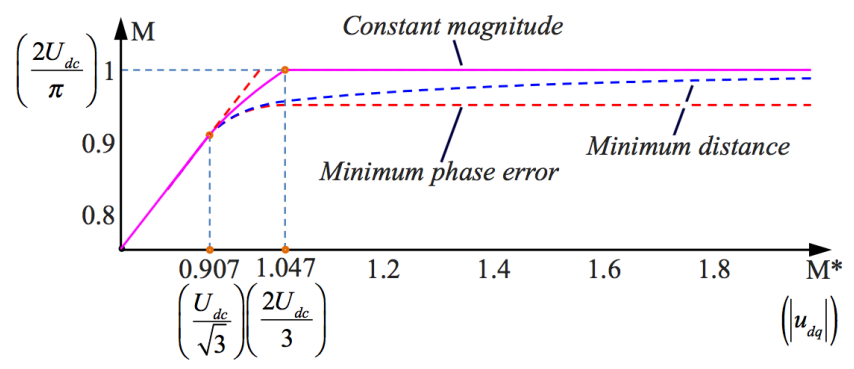

Fig. 6. Output voltage vs. voltage command magnitdue for the different overmodulation methods

As can be seen from Fig. 6, MI is saturated at 0.952 when minimum phase error overmodulation is used. It means that $4.8 \%$ of the inverter capability would be left unused. Minimum distance ovecrmodulation is equivalent to space vector PWM in nonlinear region. However, it achieves above 0.98 of MI and again didn't use all available voltage.

Output voltage must be limited whenever the voltage reference goes beyong the hexagon limits. In the limit, the six active vectors of the hexagon are used sequentially over each period of the fundamental voltage, which is referred to as six-step mode [4]-[6]. In this case all available on the inverter voltage is used.

For the transient of the voltage reference from $1 / \sqrt{3} U_{\mathbf{c}}$ to $2 / 3 U_{d x}$ the constant magnitude overmodulation [4] is adopted. If the voltage reference going beyond the linear region, but still in voltage limits hexagon, it will not change. The correction only required if vector is out of hexagon. To implement this method simple geometrical calculation is required.

Consider a reference vector with aplitude $r$ and phase $\theta$. As mentioned above, until it remains within the hexagon boundary, the trajectory can be traced by normal operation. As the amplitude $r$ increases above the $1 / \sqrt{3} U_{\mathbf{c}}$, the voltage vector must be modefied. For each sector of the hexagon, the phase can be found by the equation (1).

Fig.7 shows the voltage and current waveforms in stationary reference frame. The distortions in the current produce the torque oscillations. But it relieves additional voltage for transient process.

$$
\theta= \begin{cases}\theta_{1} & 0 \leq \theta_{1} \leq \alpha_{g} \\ \alpha_{g} & \alpha \theta_{1} \leq \pi / 6 \\ \pi / 3-\alpha_{g} & \pi / 6 \leq \theta_{1} \leq \pi / 3-\alpha_{g} \\ \theta_{1} & \pi / 3-\alpha_{g} \leq \theta_{1} \leq \pi / 3\end{cases}
$$

$$
\text { where } \alpha_{z}=\operatorname{acos}\left(\frac{U_{d c} / \sqrt{3}}{\theta_{1}}\right)
$$

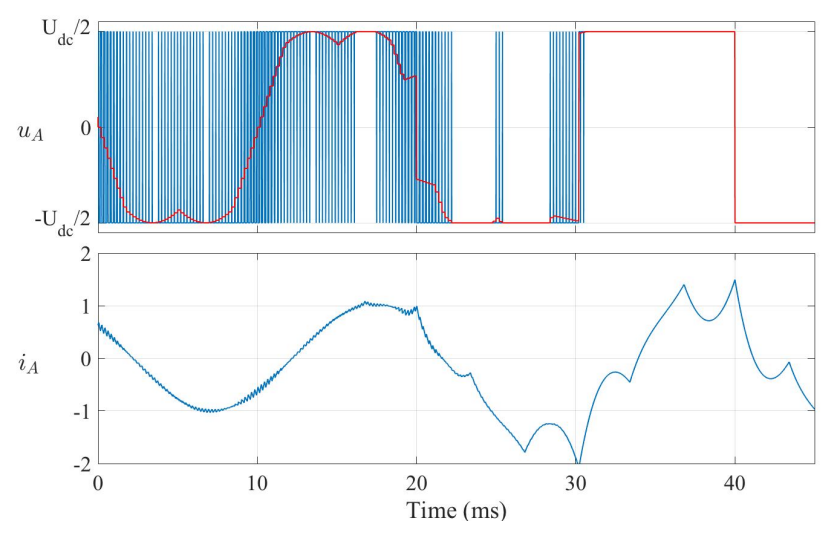

Fig. 7. Top - volage command phase and output voltage for phase A, bottom - phase current, when the inverter changes from linear operation to six-tep using constant magnitude method.

\section{SimUlation RESUlTS}

The proposed in Fig. 1 system has been simulated using $\mathrm{C}++$ model. A $2.2 \mathrm{~kW}$ IM is modeled using dinamic model in the rotor flux synchronous frame. The main model parameters is shown in table 1 . The ramp coeffitient $\mathrm{K} 2$ was obtained with current constraints only. The complex current regulator has a bandwith equal to $200 \mathrm{~Hz}$. As a grid was used three phase grid with $380 \mathrm{~V}$ phase to phase voltage and $50 \mathrm{~Hz}$. The Fig. 8 shows the response to step-like torque command. The rotor speed is equal to $1.1 \mathrm{pu}$. At the $0.02 \mathrm{~s}$ the torque command is changed from $0.1 \mathrm{pu}$ to $0.7 \mathrm{pu}$. At the same time the d-axis current command (subplot two) is changed so that use all available current to increase the rotor flux. At the time, around $0.1 \mathrm{~s}$ the voltage reference has achieved the limit value and overmodulation is used. On the fourth subplot, the actual and command torque is shown. At the moment when the voltage goes beyond the limits, the torque began to be distorted due to overmodulation.

TABLE I. INDUCTION MOTOR PARAMETERS

\begin{tabular}{cc}
\hline$R_{s}$ & $2.35 \Omega$ \\
$L_{s}$ & $0.295 \mathrm{H}$ \\
$L_{m}$ & $0.284 \mathrm{H}$ \\
$L_{r}$ & $0.295 \mathrm{H}$ \\
$R_{r}$ & $1.99 \Omega$ \\
Power Rating & $2.2 \mathrm{KW}$ \\
Poles & 4 \\
\hline
\end{tabular}




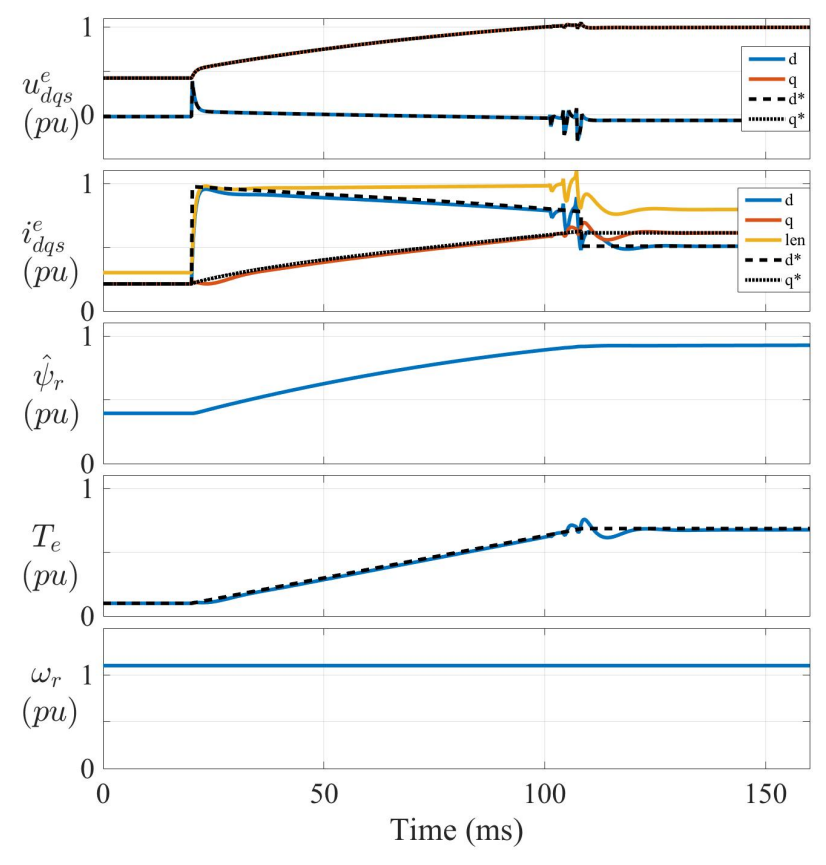

Fig. 8. The proposed scheme response to a step-like torque command from 0.1 p.u. to 0.7 p.u. at 1.1 p.u. speed. From top to bottom: voltages, currents, rotor flux, electomagnetic torque, rotor speed.

\section{CONCLUSION}

This paper analyzes dynamic response of FOC induction motors using MTPA considering voltage constraints. Machine mode with the reduced flux level has advantages and disadvanatges. Decreasing power losses is the main benefit of use MTPA. On the other hand the poore dynamic response throught the transient of command changing make it impossible to use this method in some applications. The ramp-like torque command with the optimal slope coefficient reduces the settling time and the stress of the mechanical transmition. The optimal slope coefficient was already defined for current constraints only. In this paper effect on voltage constraints on this method have been studied. The use of the constant magnitude overmodulation is proposed. The stable working of the control system is shown.

\section{REFERENCES}

[1] A. Popov, V. Lapshina, F. Briz and I. Gulyaev, "Dynamic operation of FOC induction machines under current and voltage constraints," 2017 19th European Conference on Power Electronics and Applications (EPE'17 ECCE Europe), Warsaw, 2017, pp. 1-10.

[2] A. Popov, V. Lapshina, I. Gulyaev and F. Briz, "Improving the dynamic response of FOC induction machines operated with reduced rotor flux," 2018 25th International Workshop on Electric Drives: Optimization in Control of Electric Drives (IWED), Moscow, Russia, 2018, pp. 1-4.

[3] F. Briz, A. B. Diez, M. W. Degner, R. D. Lorenz, "Current and Flux Regulation in Field Weakening Operation", IEEE Transactions on Industry Applications, vol.: 37, $\mathrm{n}^{\mathrm{o}}$ 1, pp. 42-50, Jan. 2001

[4] P. Y. Lin and Y. S. Lai, "Voltage control technique for the extension of DC-link voltage utilization of finite-speed SPMSM drives," IEEE Trans. Ind. Electron., vol. 59, no. 9, pp. 3392-3402, Sep. 2012.

[5] J. Holtz, W. Lotzkat, and A. Khambadkone, "On continuous control of PWM inverters in the overmodulation range including the six-step mode," IEEE Trans. Power Electron., vol. 8, pp. 546-553, Oct. 1993.

[6] R. J. Kerkman, D. Leggate, B. J. Seibel, and T. M. Rowan, "An overmodulation strategy for PWM voltage inverters," in Proc. 19th Annu. Int. Conf. Industrial Electronics, Control and Instrumentation (IECON'93), Maui, HI, 1993, pp. 1215-1221.

[7] R .J. Kerkman, D. Leggate, T. M. Rowan, and B. J. Seibel, "Control of PWM voltage inverters in the pulse dropping region," in Proc. 9th Annu. Applied Power Electronics Conf. and Exposition (APEC '94), Orlando, FL, 1994, pp. 521-528.

[8] S. Bolognani and M. Zigliotto, "Novel digital continuous control of SVM inverters in the overmodulation range," IEEE Trans. Ind. Appl., vol. 33, no. 2, pp. 525-530, Mar./Apr. 1997. istep

[9] Y. Kwon, S. Kim and S. Sul, "Six-Step Operation of PMSM With Instantaneous Current Control," IEEE Transactions on Industry Applications, vol. 50, no. 4, pp. 2614-2625, July-Aug. 2014.

[10] Y. Liu and A. Bazzi, "Improved maximum torque-per-ampere control of induction machines by considering iron loss", 2017 IEEE International Electric Machines and Drives Conference (IEMDC), Miami, FL, 2017, pp. 1-6. 